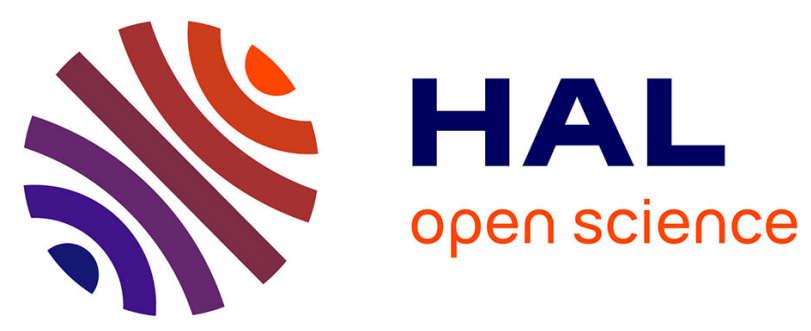

\title{
CT-pro-AVP as a tool for assessment of intravascular volume depletion in severe hyponatremia
}

Guilaine Boursier, Marion Alméras, Delphine Buthiau, Sébastien Jugant, Delphine Daubin, Nils Kuster, Anne-Marie Dupuy, Jean Ribstein, Kada Klouche, Jean-Paul Cristol

\section{To cite this version:}

Guilaine Boursier, Marion Alméras, Delphine Buthiau, Sébastien Jugant, Delphine Daubin, et al.. CTpro-AVP as a tool for assessment of intravascular volume depletion in severe hyponatremia. Clinical Biochemistry, 2015, 48 (10-11), pp.640-645. 10.1016/j.clinbiochem.2015.03.013 . hal-01756499

\section{HAL Id: hal-01756499 \\ https://hal.umontpellier.fr/hal-01756499}

Submitted on 25 Jul 2018

HAL is a multi-disciplinary open access archive for the deposit and dissemination of scientific research documents, whether they are published or not. The documents may come from teaching and research institutions in France or abroad, or from public or private research centers.
L'archive ouverte pluridisciplinaire HAL, est destinée au dépôt et à la diffusion de documents scientifiques de niveau recherche, publiés ou non, émanant des établissements d'enseignement et de recherche français ou étrangers, des laboratoires publics ou privés. 


\title{
CT-pro-AVP as a tool for assessment of intravascular volume depletion in severe hyponatremia
}

\author{
Guilaine Boursier ${ }^{\mathrm{a}, \mathrm{b}}$, Marion Alméras a , Delphine Buthiau ${ }^{\mathrm{a}}$, Sébastien Jugant ${ }^{\mathrm{c}}$, Delphine Daubin ${ }^{\mathrm{d}}$, Nils Kuster ${ }^{\mathrm{a}, \mathrm{b}}$, \\ Anne-Marie Dupuy ${ }^{\mathrm{a}}$, Jean Ribstein ${ }^{\mathrm{c}}$, Kada Klouche ${ }^{\mathrm{b}, \mathrm{d}, 1}$, , Jean-Paul Cristol $^{\mathrm{a}, \mathrm{b}, *, 1}$ \\ a Department of Biochemistry and Hormonology, CHU Montpellier, Montpellier, 34295, France \\ b UMR CNRS 9214 - Inserm U1046, Physiologie et Médecine Expérimentale du cœur et des muscles - PHYMEDEXP, Université de Montpellier, Montpellier, France \\ c Department of Internal Medicine, CHU Montpellier, Montpellier, 34295, France \\ d Department of Intensive Care Medicine, CHU Montpellier, Montpellier, 34295, France
}

\section{A B S T R A C T}

Background: Assessment of volume status is essential to best manage hyponatremic patients but is not always accurate in clinical practice. The aim of this study was to evaluate the reliability of C-terminal portion of pro-arginine-vasopressin (CT-pro-AVP), a surrogate biomarker of vasopressin release, in assessing intravascu-lar volume (IVV) depletion in hypoosmolar hyponatremic patients.

Methods: Plasma CT-pro-AVP and urea-to-creatinine ratio (Ur/Cr) were performed in 131 hospitalized patients presenting chronic severe hypoosmolar hyponatremia. At hospital discharge, their IVV was evaluated regardless of CT-pro-AVP concentrations. All patients were then classified as decreased or as normal/expanded IVV group.

Results: Plasma CT-pro-AVP levels were higher in patients with decreased IVV (34.6 vs. $11.3 \mathrm{pmol} / \mathrm{L}, \mathrm{p}<0.001$ ) and exhibited a reliable performance for assessment of decreased IVV (ROC AUC at 0.717 [95\% CI 0.629-0.805]). The combination of CT-pro-AVP and Ur/Cr resulted in an improved ROC AUC up to 0.787 (95\%CI 0.709-0.866).

Conclusions: Our findings support the hypothesis that CT-pro-AVP plasma level may reflect IVV and would be a tool for its assessment. This performance has been magnified by its combination with $\mathrm{Ur} / \mathrm{Cr}$. A dual-marker strategy may help clinicians to optimize the management of severe hyponatremia especially in case of confusing clinical presentations.

Keywords:

CT-pro-AVP

Hyponatremia

Intravascular volume

Hypovolemia

\section{Introduction}

Hyponatremia, defined as a plasma sodium concentration of less than $135 \mathrm{mmol} / \mathrm{L}$, occurs frequently in hospitalized patients and has prognostic implications. A recent study of 13,276 Intensive Care Unit patients reported the prevalence of hyponatremia at $12.9 \%$ and of severe hyponatremia (sodium level $\leq 125 \mathrm{mmol} / \mathrm{L}$ ) at $5.9 \%$. Hospital mortality reached more than $40 \%$ among these severe patients [1]. This mortality was not only due to the associated cause of hyponatremia but also to its therapeutic management. Indeed, the evaluation of hyponatremia is not always accurate because of the lack of constant and specific signs. In the study of Hula et al., significant management errors were reported in 33\% of hyponatremia and conferred a higher mortality [2].

Abbreviations: AVP, arginine vasopressin; CT-pro-AVP, C-terminal pro-arginine vasopressin; ECV, extracellular volume; FENa, fractional sodium excretion; IVV, intravascular volume; $\mathrm{Ur} / \mathrm{Cr}$, urea-to-creatinine ratio.

* Corresponding author at: Department of Biochemistry and Hormonology, Lapeyronie University Hospital, Montpellier, France.

E-mail address: jp-cristol@chu-montpellier.fr (J.-P. Cristol).

1 The authors have equally contributed to this work.
Hypotonic hyponatremia is an imbalance of water and sodium homeostasis induced by a proportional excess of total body water relative to the total body sodium [3-5]. The assessment of effective intravascular volume (IVV) is a main condition to decide appropriate treatment as rehydration [5]. The routine approach consists of patient's history and physical examination but the assessment of volume status is not always reliable and the distinction between total extracellular volume (ECV) and effective IVV status is difficult in clinical practice [4-6]. In fact, as seen in Fig. 1, an expanded ECV could be associated with a decreased IVV, such as congestive heart failure, hepatic cirrhosis, and nephrotic syndrome, or with an expanded IVV such as renal failure.

Arginine vasopressin (AVP) is one of the key hormones of water homeostasis. Urine sodium concentration and osmolality are usually measured to assess its activity. The suppression of AVP activity by increased IVV generally results in urine osmolality $<100 \mathrm{mOsm} / \mathrm{kg}$ [5], while its stimulation by hypovolemia increases urine osmolality above serum osmolality. Consequently, urine osmolalities between $100 \mathrm{mOsm} / \mathrm{kg}$ and the level of plasma osmolality represent a gray area in which it is difficult to precisely assess fluid status [5,7]. However, urine analysis is influenced by diuretics and urine samples are often difficult to be 


\begin{tabular}{|c|c|c|c|c|c|c|}
\hline & \multicolumn{6}{|c|}{$\begin{array}{c}\text { History } \\
\text { Physical examination } \\
\text { Blood \& Urine analysis }\end{array}$} \\
\hline IVV compartment & \multicolumn{3}{|c|}{ Low IVV } & \multicolumn{3}{|c|}{ Normal or Expanded IVV } \\
\hline \multirow[t]{3}{*}{ ECV compartment } & & w ECV & High ECV & High ECV & Norm & lal ECV \\
\hline & $\begin{array}{l}\text { Extra renal } \\
\underline{\text { losses }} \\
\text { Vomiting, } \\
\text { diarrhea, } \\
\text { pancreatitis, } \\
\text { peritonitis, } \\
\text { malnutrition. }\end{array}$ & $\begin{array}{c}\text { Renal losses } \\
\text { Diuretic excess, } \\
\text { mineralocorticoid } \\
\text { deficiency, salt- } \\
\text { losing nephritis, } \\
\text { renal tubular } \\
\text { acidosis, ketonuria, } \\
\text { osmotic diuresis, } \\
\text { cerebral salt } \\
\text { wasting. }\end{array}$ & $\begin{array}{l}\text { Third spacing } \\
\text { Cardiac } \\
\text { failure, liver } \\
\text { cirrhosis, } \\
\text { nephrotic } \\
\text { syndrome. }\end{array}$ & $\begin{array}{l}\text { Renal failure } \\
\text { Acute or chronic } \\
\text { renal failure. }\end{array}$ & $\begin{array}{l}\text { Primary } \\
\text { polydipsia, } \\
\text { poor dietary } \\
\text { intake, } \\
\text { potomania }\end{array}$ & $\begin{array}{l}\text { Glucocorticoid } \\
\text { deficiency, } \\
\text { hypothyroidism, } \\
\text { stress, drugs, } \\
\text { syndrome of } \\
\text { inappropriate } \\
\text { secretion of } \\
\text { antidiuretic } \\
\text { hormone. }\end{array}$ \\
\hline & \multicolumn{3}{|c|}{ Appropriate AVP stimulation } & \multicolumn{2}{|c|}{ AVP suppression } & $\begin{array}{l}\text { Inappropriate } \\
\text { AVP stimulation }\end{array}$ \\
\hline
\end{tabular}

Fig. 1. Intracellular and extracellular volume fluid status depending on mechanisms of subsequent hyponatremia. Abbreviations: IVV, intracellular fluid volume; ECV, extracellular fluid volume; and AVP, arginine vasopressin.

taken, especially in emergency units. Direct measurement of endogenous AVP in plasma could be therefore useful to assess IVV [8,9], but it is not suitable for use in clinical practice due to the binding of AVP to platelets and its unstability in isolated plasma [10,11]. In contrast, the C-terminal portion of provasopressin (CT-pro-AVP), which is co-secreted with AVP, is much easier to quantify. CT-pro-AVP is a 39-amino acid glycopeptide that may have a role during the intracellular processing of provasopressin. It is produced together with AVP in an equimolar ratio and has similar kinetics as described for AVP. CT-pro-AVP is now frequently used as a surrogate marker for AVP secretion in clinical studies [8-12].

The aim of this study was therefore to evaluate the reliability of the plasma CT-pro-AVP concentration in assessing IVV status in hypoosmolar hyponatremic patients. Our hypothesis was that CT-proAVP may reflect IVV and should help for the management of severe hyponatremia. If IVV is decreased, AVP levels, and so CT-pro-AVP levels, should dramatically increase much more than in the case of syndrome of inappropriate secretion of antidiuretic hormone or in the case of expanded IVV (in which CT-pro-AVP concentrations should decrease). We sought also to compare it to routine biological parameters used to diagnosis hyponatremia in clinical settings including the ratio of plasma urea to plasma creatinine [13-15].

\section{Patients and methods}

\section{Study design and population}

All hospitalized patients presenting hyponatremia at the University Hospital of Montpellier between July 2012 and January 2013 were screened for the study. Inclusion criteria included an age older than 18 years and a chronic ( $\geq 48 \mathrm{~h}$ ) severe hypoosmolar hyponatremia defined as a plasma sodium concentration less than $125 \mathrm{mmol} / \mathrm{L}$ and a plasma osmolality less than $275 \mathrm{mOsm} / \mathrm{kg}$. Patients with renal failure with an estimated glomerular filtration rate $<15 \mathrm{~mL} / \mathrm{min} / 1.73 \mathrm{~m}^{2}$ were not eligible. The study was performed according to the principles of the Declaration of Helsinki and was approved by the local ethics committee. Demographic, clinical and laboratory data were collected during hospitalization. All laboratory values ( plasma glucose, creatinine, urea, urine sodium excretion and urine osmolality) were collected upon the occurrence of hypoosmolar hyponatremia within first sodium measurement.

\section{Diagnostic criteria and classification}

The assessment of the ECV, IVV and body sodium compartments was reinterpreted after the discharge of patients by three trained investigators (KK, JPC, SJ) using weight (at admission and at discharge), clinical picture (orthostatic hypotension, clinical signs of dehydration, history), therapeutic management (including saline loads), response to treatment, biology (urinary sodium concentration), and final diagnosis according to consensus-based clinical recommendations [4,5]. All patients were classified into one of the two categories depending on IVV status as shown in Fig. 1: 1) Decreased IVV and 2) Normal or expanded IVV. The investigators were blinded to results of plasma CT-pro-AVP measurements.

\section{Laboratory assessment}

Blood samples were collected into lithium heparin tubes and were processed at the clinical chemistry laboratory. A plasma aliquot was stored at $-20{ }^{\circ} \mathrm{C}$ for later analysis. Routine laboratory parameters were measured by automated Cobas 8000 analyzer (Roche Diagnostics, Meylan, France). Urine and plasma samples were analyzed using ionselective electrodes for sodium. The glutamate dehydrogenase and hexokinase method were used for the determination of plasma urea and glucose levels and IDMS-traceable creatinine enzymatic assays was used for plasma creatinine measurement. Osmolality was measured with an osmometer by means of freezing point depression (ThermoFisher Scientific, Clichy, France). The effective osmolality was obtained as serum osmolality less serum urea level in millimoles per liters $[16,17]$. Plasma urea-to-creatinine ratio was calculated by the formula: (urea $(\mathrm{mmol} / \mathrm{L}) /$ creatinine $(\mu \mathrm{mol} / \mathrm{L})) \times 10^{3}[13-15]$. The fractional sodium excretion (FENa) was calculated by the formula: $100 \times[$ urinary sodium $(\mathrm{mmol} / \mathrm{L}) \times($ plasma creatinine $(\mu \mathrm{mol} / \mathrm{L}) /$ $1000)] /$ [plasma sodium $(\mathrm{mmol} / \mathrm{L}) \times$ urinary creatinine $(\mathrm{mmol} / \mathrm{L})]$.

The CT-pro-AVP was performed from frozen lithium heparin plasma samples using the CT-pro-AVP assay on the Kryptor Compact Plus systems (Thermofisher Scientific, Clichy, France) which allows a time to result of $18 \mathrm{~min}$ as previously described [18]. For values between 3 and $16 \mathrm{pmol} / \mathrm{L}$, within- and between-assay imprecision ranged from $2.4 \%$ to $11.3 \%$ and from $3.9 \%$ to $10.2 \%$, respectively. The LoD was $1.90 \mathrm{pmol} / \mathrm{L}$ in our conditions. 


\section{Data analysis}

Characteristics of study patients are presented as frequencies (percent) for categorical variables and median (interquartile range, IQR) for continuous variables. Patient groups were compared using Wilcoxon test for continuous variables and Fisher's exact test for categorical variables. Age and sex adjusted linear regression was used to compare CT-pro-AVP, urea to creatinine ratio $(\mathrm{Ur} / \mathrm{Cr}$ ), fractional sodium excretion (FENa) and urinary osmolality values according to IVV status. Regression coefficients with 95\% confidence intervals (CI) were determined. Overall diagnostic values were quantified by calculating the area under the receiver operating characteristic (ROC) curve (AUC) using the trapezoidal method, with 95\% CI computed by using the Delong method. Comparison between AUCs was performed through the Delong test for correlated ROC curves. Sensitivity, specificity, and predictive values were calculated along with $95 \% \mathrm{CI}$ based on binomial distribution. Optimal CT-pro-AVP thresholds were determined using the Youden index. The significance level was set at 5\% for all tests. Statistical analysis was performed using R 2.15 (R Foundation for Statistical Computing, Vienna, Austria).

\section{Results}

\section{Characteristics of population study}

A total of 131 hypoosmolar hyponatremic patients were included into the study. Their median age was at 71 years with a slight predominance of females (58\%). Plasma sodium concentrations ranged between 102 and $125 \mathrm{mmol} / \mathrm{L}$. Median (IQR) measured and effective osmolality were at 260 (249-269) and 252 (244-259) mOsm/kg respectively, whereas median urinary osmolality was at 295 (233-487) mOsm $/ \mathrm{kg}$ and median FENa was $0.6(0.2-1.3) \%$. All other characteristics of study population are displayed in Table 1 . Hyponatremia was induced by sodium depletion due to renal or non-renal losses in $29 \%$, water and sodium expansion with third spacing or oliguria in $34 \%$, syndrome of inappropriate secretion of antidiuretic hormone in $23 \%$ and high water with low solute intake in $14 \%$ of the patients.

\section{Comparison of the two groups depending on IVV status}

Table 1 provides the characteristics of the hyponatremic patients divided into groups depending on IVV status. Within the 73 patients who had a hyponatremia associated with a decreased IVV, 36 (49.3\%) had a high ECV. The comparison between groups with decreased IVV and with normal or expanded IVV showed no differences regarding to age, sex, natremia and natriuresis, FENa and urinary osmolality (Table 1 and Fig. 2A, B). In addition, percentage of patients with a FENa $\leq 1 \%$ was not significantly different between the two groups
(23.8\% in patients with decreased IVV and $37.5 \%$ in patients with normal or expanded IVV). By contrast, plasma urea, plasma creatinine and $\mathrm{Ur} / \mathrm{Cr}$ ratio were significantly higher in the decreased IVV group (Fig. 2C). Indeed, $\mathrm{Ur} / \mathrm{Cr}$ ratios were 1.3 fold higher in patients with decreased IVV than patients with normal or expanded IVV; independently of age and sex according to linear regression analysis.

In all our hyponatremic population, median plasma CT-pro-AVP level was $22.1 \mathrm{pmol} / \mathrm{L}$ and ranged from 1.9 to $1073 \mathrm{pmol} / \mathrm{L}$. The values differed significantly between groups according to IVV status as shown in Fig. 2D. A doubling of plasma CT-pro-AVP levels (34.6 vs. $11.3 \mathrm{pmol} / \mathrm{L}$ ) was observed in patients in whom IVV was judged decreased, than others. By linear regression analysis, the association of CT-pro-AVP with decreased IVV status was independent of age and sex.

Diagnostic performance of CT-pro-AVP, FENa and Ur/Cr for assessment of IVV

Sensitivity and specificity for assessment of decreased IVV are reported in Table 2. Decision thresholds were determined using the 99th percentile of a general population (CT-pro-AVP $>18.9 \mathrm{pmol} / \mathrm{L}$ ) or empiric values $(\mathrm{Ur} / \mathrm{Cr}>100, \mathrm{FENa} \leq 1 \%)$. The diagnostic performance of FENa was poorer than $\mathrm{Ur} / \mathrm{Cr}$ ratio, thus we used $\mathrm{Ur} / \mathrm{Cr}$ levels as a validated determinant of IVV extracellular body volume status. In addition, CT-pro-AVP plasma concentrations and $\mathrm{Ur} / \mathrm{Cr}$ levels were independent of each other. Since both plasma $\mathrm{Ur} / \mathrm{Cr}$ ratio and CT-proAVP levels significantly distinguished between the two groups, we tested their performance in isolated manner or in combination for the assessment of IVV depletion in all hyponatremic patients. The ROC AUC was 0.717 (95\% CI. 0.629-0.805) for CT-pro-AVP concentrations and 0.698 (95\% CI, 0.608-0.788) for $\mathrm{Ur} / \mathrm{Cr}$ and it was not significantly different. Combining CT-pro-AVP with $\mathrm{Ur} / \mathrm{Cr}$ resulted in improved ROC AUC up to 0.787 (95\% CI. 0.709-0.866) with a significant difference compared with that of $\mathrm{Ur} / \mathrm{Cr}(\mathrm{p}=0.011)$ and CT-pro-AVP (Fig. 3). Using the Youden index, the thresholds to distinguish decreased IVV from others were $16.3 \mathrm{pmol} / \mathrm{L}$ and 91.9 for CT-pro-AVP and $\mathrm{Ur} / \mathrm{Cr}$ respectively. As seen in Table 2, adding CT-pro-AVP to $\mathrm{Ur} / \mathrm{Cr}$, set at a cut-off value of $18.9 \mathrm{pmol} / \mathrm{L}$ and 100 respectively, increased specificity for decreased IVV assessment from $83.9 \%$ to $94.6 \%$.

\section{Discussion}

Investigating 131 patients with severe hyponatremia, we found that CT-pro-AVP plasma concentrations, as well as plasma $\mathrm{Ur} / \mathrm{Cr}$ ratio, were significantly elevated in those with decreased IVV. Our results indicate also that plasma CT-pro-AVP levels are a better discriminant than $\mathrm{Ur} / \mathrm{Cr}$ ratio for the assessment of IVV status and that the combination of both levels improved significantly their specificity.

Table 1

Baseline characteristics of the study population.

\begin{tabular}{|c|c|c|c|c|}
\hline Patient's characteristics & Total & Decreased IVV & Normal or expanded IVV & $\mathrm{p}$ value \\
\hline Diagnosis & $131(100)$ & $73(55.7)$ & $58(44.3)$ & \\
\hline Sex & & & & 0.724 \\
\hline Male & $58(44.3)$ & $31(42.5 \%)$ & $27(46.6 \%)$ & \\
\hline Female & $73(55.7)$ & $42(57.5 \%)$ & $31(53.4 \%)$ & \\
\hline Age, years & $71(58-84)$ & $76(58-86)$ & $66(58-81)$ & 0.145 \\
\hline Plasma sodium, mmol/L & $121(117-124)$ & $121(118-123)$ & $122(116-124)$ & 0.893 \\
\hline Measured plasma osmolality, mOsm/kg & 260 (249-269) & $264(252-275)$ & $255.5(243-263)$ & 0.001 \\
\hline Effective plasma osmolality, mOsm/kg & $252(244-259)$ & $255(247-261)$ & $250(239-256)$ & 0.009 \\
\hline Glycemia, $\mathrm{mmol} / \mathrm{L}$ & $6.3(5.2-7.8)$ & $6.4(5.6-8.6)$ & $6.1(5.0-7.4)$ & 0.087 \\
\hline Plasma urea, mmol/L & $5.7(3.7-10.4)$ & $7.2(5.4-13.5)$ & $4.4(3.02-5.9)$ & $<0.001$ \\
\hline Creatininemia, $\mu \mathrm{mol} / \mathrm{L}$ & $69.0(49.0-100.0)$ & $84.0(61.0-111.0)$ & $60.5(44.3-72.0)$ & $<0.001$ \\
\hline Urinary sodium, $\mathrm{mmol} / \mathrm{L}$ & $43(17-68)$ & $30(16-66)$ & $44(21-68)$ & 0.334 \\
\hline
\end{tabular}

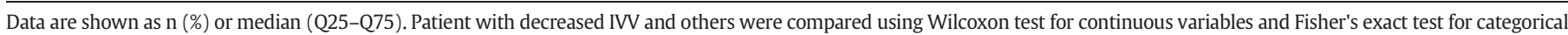
variables with a significance level of $5 \%$.

Abbreviation: IVV, intracellular fluid volume. 

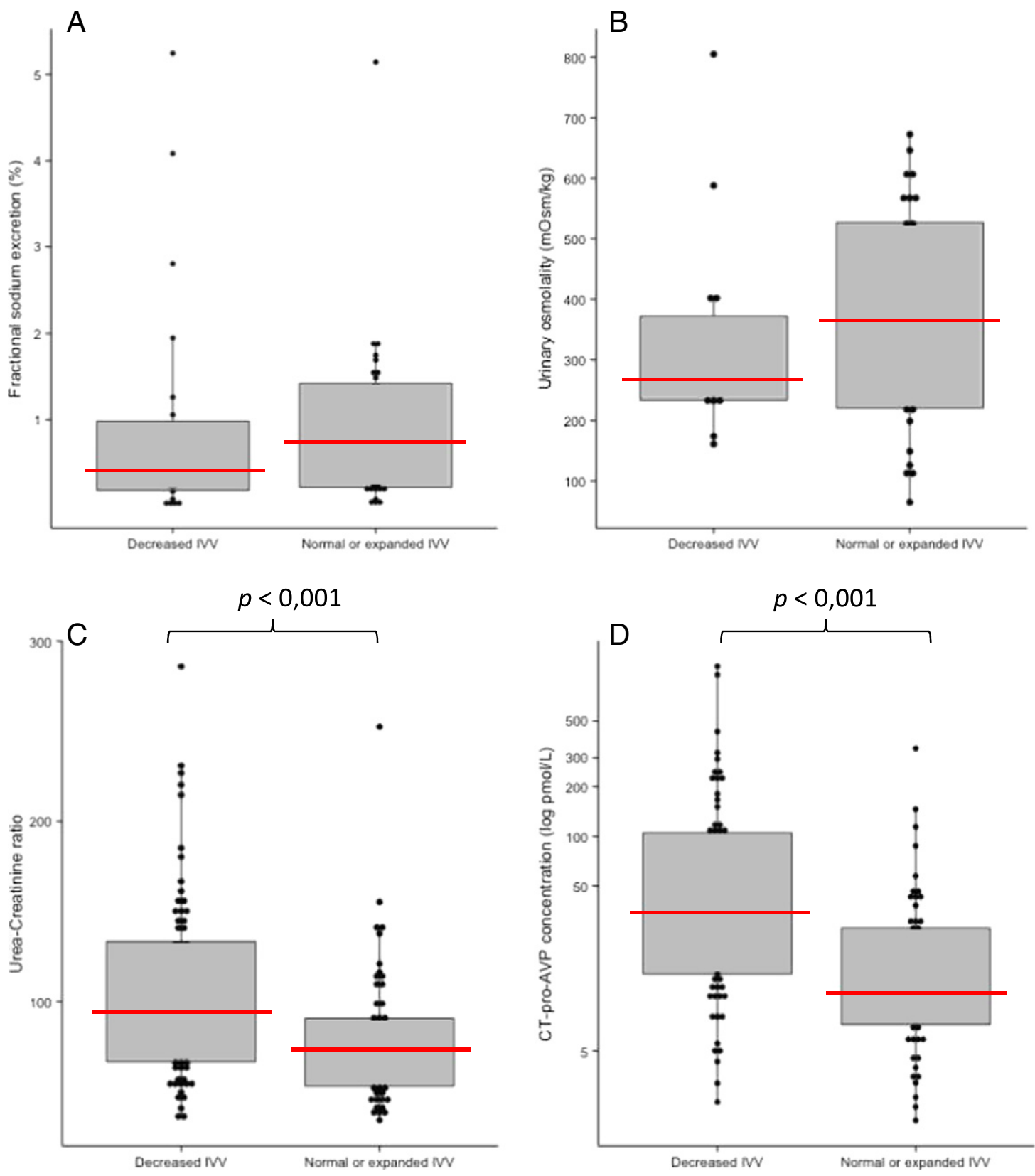

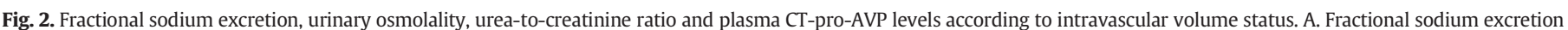

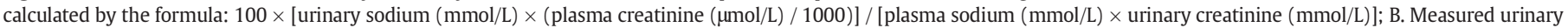

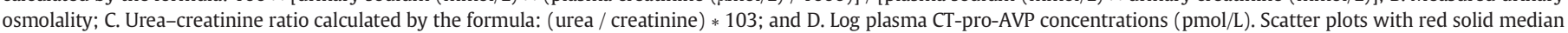

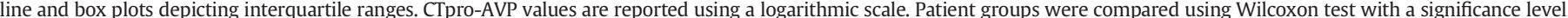

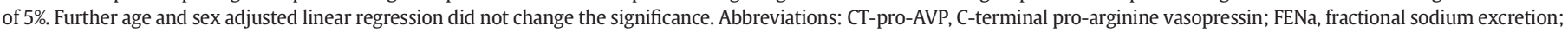
and IVV, intracellular fluid volume.

Hyponatremia is the most common electrolyte disorder in clinical medicine and is associated with substantial morbidity and mortality. A precise diagnostic evaluation for initiation of the adequate treatment is the sole condition to guarantee the best outcome. The diagnosis based on clinical signs and routine laboratory parameters has a limited sensitivity and specificity [19]. Readily available and reliable parameters for the differential diagnosis of hyponatremia are therefore needed to facilitate a timely therapeutic strategy.

Hyponatremia often develops as a consequence of water intake associated with water retention due to elevated levels of AVP [20,21]. The amount of plasma AVP is regulated by osmotic and non-osmotic stimuli namely the blood volume contraction. When decreased osmolality and IVV (more than 10\%) occurs simultaneously, AVP release is not suppressed in order to maintain primarily blood volume. Thus, in hyponatremia, AVP levels are either appropriately (in case of decreased IVV) or inappropriately (in syndrome of inappropriate secretion of antidiuretic hormone) elevated in relation to osmolar status (Fig. 1). The persistence of AVP release due to non-osmotic hemodynamic stimuli is predominantly responsible for water retention and hyponatremia with decreased IVV, as well as in edema-forming disorders such as heart failure, liver cirrhosis and nephrotic syndrome [3]. It is then questionable whether there is a cut off differentiating appropriate and inappropriate AVP increases and whether AVP measurement is helpful in the differential diagnosis of hyponatremia. The measurement of AVP is however cumbersome. CT-pro-AVP is produced in equimolar amounts to AVP and its levels mirror AVP levels. CT-pro-AVP also shows parallel changes during disordered water states as shown for AVP [10,11]. As compared to AVP, CT-pro-AVP is very stable in plasma and serum and 
Table 2

Diagnostic performance of CT-pro-AVP and $\mathrm{Ur} / \mathrm{Cr}$ and their combination for assessment of IVV depletion.

\begin{tabular}{lllll}
\hline Decision rule & Specificity & Sensitivity & PPV & NPV \\
\hline CT-pro-AVP $>18,9$ pmol/L & $62.5 \%$ & $66.7 \%$ & $70.4 \%$ & $58.3 \%$ \\
Ur $/ \mathrm{Cr}>100$ & $83.9 \%$ & $46.7 \%$ & $79.5 \%$ & $54.0 \%$ \\
Fractional sodium excretion $\leq 1 \%$ & $62.8 \%$ & $23.8 \%$ & $28.0 \%$ & $55.5 \%$ \\
CT-pro-AVP $>18,9 \mathrm{pmol} / \mathrm{l}$ AND $\mathrm{Ur} / \mathrm{Cr}>100$ & $94.6 \%$ & $29.3 \%$ & $88.0 \%$ & $50.0 \%$ \\
CT-pro-AVP $>18,9 \mathrm{pmol} / \mathrm{l}$ OR Ur $/ \mathrm{Cr}>100$ & $51.8 \%$ & $84.0 \%$ & $70.0 \%$ & $70.7 \%$
\end{tabular}

$\mathrm{N}=131$ hospitalized patients. Performance values are shown along with $95 \% \mathrm{CI}$.

Decision thresholds were determined using the 99th percentile of a general population (CT-pro-AVP $>18.9 \mathrm{pmol} / \mathrm{L}$ ) or empiric values $(\mathrm{Ur} / \mathrm{Cr}>100, \mathrm{FENa} \leq 1 \%$ ).

Abbreviations: CT-pro-AVP, C-terminal pro-arginine vasopressin; $\mathrm{Ur} / \mathrm{Cr}$, urea to creatinine ratio; FENa, fractional sodium excretion; PPV, positive predictive value; NPV, negative predictive value; and $\mathrm{CI}$, confidence interval.

can be easily determined including with a fully automatized assay such as Kryptor Compact Plus [18], which have performances closed to those of the reference method initially developed [12]. Consequently, CT-proAVP appears as a new promising diagnostic tool in the differential diagnosis of patients with hypoosmolar hyponatremia.

In our study, median CT-pro-AVP values were significantly higher in patients with decreased IVV compared with other groups. In case of decreased IVV, CT-pro-AVP levels were indeed above the 99th percentile of a general population $(18.9 \mathrm{pmol} / \mathrm{L}$ according to the most recent study) [22]. These data extend the previous observations by Fenske et al. [23] suggesting that CT-pro-AVP levels are higher in hyponatremic patients with sodium depletion when compared to syndrome of inappropriate secretion of antidiuretic hormone patients or control patients. Nevertheless, we observed a large overlap in CTpro-AVP values and CT-pro-AVP sensitivity and specificity do not allow to reliably differentiate between all hyponatremia causes. Few of our hyponatremic patients showed a normal level of their basal CTpro-AVP, as described in healthy population $(<7.1 \mathrm{pmol} / \mathrm{L}$ in women and $<9.4 \mathrm{pmol} / \mathrm{L}$ in men) [12], stressing the fact that several causes may be involved in the same patient inducing a multifactorial AVP stimulation.

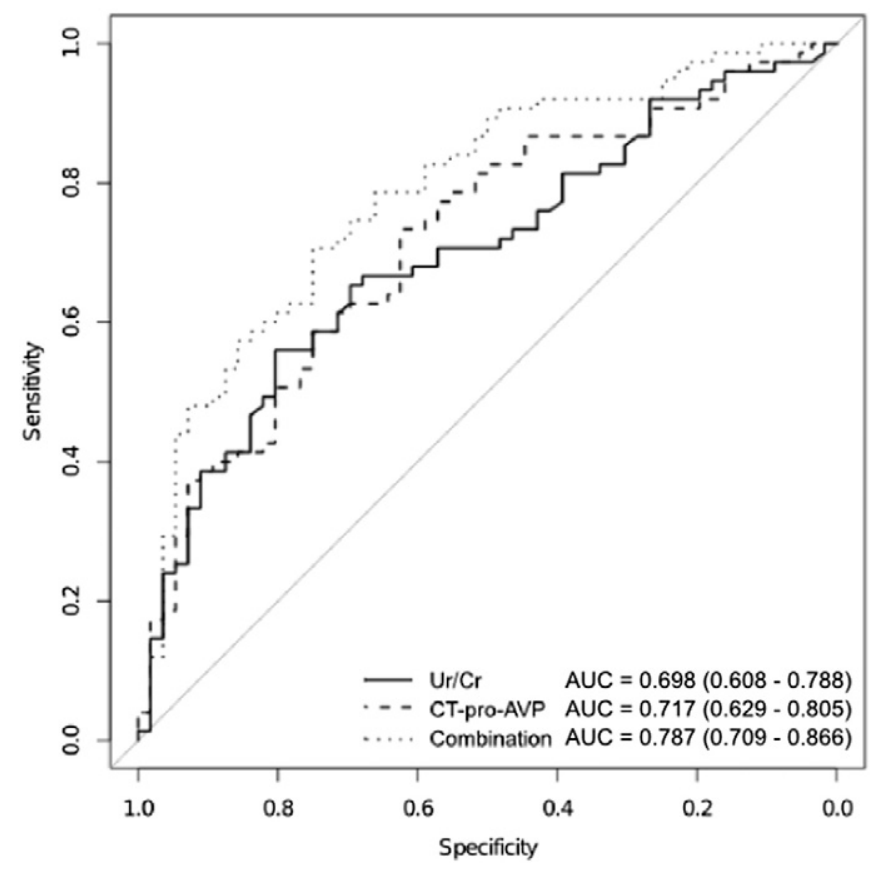

Fig. 3. Receiver operating curve analysis of individual or combined CT-pro-AVP and $\mathrm{Ur} / \mathrm{Cr}$ ratio for assessment of intravascular volume depletion. Abbreviations: CT-pro-AVP, C-terminal pro-arginine vasopressin; and $\mathrm{Ur} / \mathrm{Cr}$, Urea to creatinine ratio.
In routine evaluation of hyponatremic patients, plasma $\mathrm{Ur} / \mathrm{Cr}$ ratio has been used as a marker of IVV in several studies [13-15]. We confirmed herein that $\mathrm{Ur} / \mathrm{Cr}$ ratio is significantly higher in patients with a decreased IVV compared to others with, however, a relatively weak AUC and sensitivity. Urea levels depend on dehydration but are also linked to protein degradation while creatinine generation is related to muscle metabolism. In addition, the relationship between dehydration and $\mathrm{Ur} / \mathrm{Cr}$ ratio would vary according to gender, race, or occurrence of atrial fibrillation [13]. These observations may explain, at least for a part, the poor sensitivity of $\mathrm{Ur} / \mathrm{Cr}$ ratio alone for IVV assessment. It has been suggested that $\mathrm{Ur} / \mathrm{Cr}$ ratio should be used in combination with other indexes such as urinary/serum osmolality [14]. In our study, we investigated an original diagnostic approach with a dual-marker (plasma CT-pro-AVP with a cut-off value at the 99th percentile and $\mathrm{Ur} / \mathrm{Cr}$ ) to identify decreased IVV in hypoosmolar hyponatremic patients. We found that markers are both effective but their combination is more effective. This combined index improves both AUC and specificity compared with $\mathrm{Ur} / \mathrm{Cr}$ or CT-pro-AVP alone.

This work is a pilot study and limitations should be underlined. First of all, the IVV is only assessed by clinical parameters and not by reference methods such as isotopic one which cannot be used in clinical practice. Imaging methods were not available to assess IVV status. Second, our study is a monocentric observational study with a relatively small number of patients.

In clinical practice, the precise evaluation of IVV is of paramount importance to avoid errors in hyponatremia management including diuretic abuse and erroneous fluid restriction or intravenous fluid infusion. Since IVV status is often difficult to evaluate at the bedside, a simple plasma biomarker would be helpful to determine appropriate therapeutic option in such a circumstance. Our findings support the hypothesis that CT-pro-AVP, as a surrogate for AVP release, may reflect IVV and the combination of CT-pro-AVP with $\mathrm{Ur} / \mathrm{Cr}$ ratio would be even better. A strategy considering CT-pro-AVP and $\mathrm{Ur} / \mathrm{Cr}$ measures could be relevant in some difficult clinical presentations of hyponatremia but further studies are needed to confirm the reliability of CT-pro-AVP and $\mathrm{Ur} / \mathrm{Cr}$ levels in management of hypoosmolar hyponatremia.

\section{Conflict of interest}

The authors declare no financial or competing interests.

\section{Acknowledgment}

The authors would like to thank the nursing, technical, and medical staff at the critical care unit, internal medicine department and biochemistry laboratory for their assistance throughout the study. The CT-pro-AVP reagents used in this study were kindly provided by B.R.A.H.M.S., France.

\section{References}

[1] Vandergheynst F, Sakr Y, Felleiter P, Hering R, Groeneveld J, Vanhems P, et al Incidence and prognosis of dysnatraemia in critically ill patients: analysis of a large prevalence study. Eur J Clin Invest 2013;43(9):933-48.

[2] Huda MSB, Boyd A, Skagen K, Wile D, van Heyningen C, Watson I, et al. Investigation and management of severe hyponatraemia in a hospital setting. Postgrad Med J Mar 2006;82(965):216-9.

[3] Schrier RW. Water and sodium retention in edematous disorders: role of vasopressin and aldosterone. Am J Med juillet 2006;119(7, Suppl. 1):S47-53.

[4] Verbalis JG, Goldsmith SR, Greenberg A, Korzelius C, Schrier RW, Sterns RH, et al. Diagnosis, evaluation, and treatment of hyponatremia: expert panel recommendations. Am J Med Oct 2013;126(10, Suppl. 1):S1-S42.

[5] Spasovski G, Vanholder R, Allolio B, Annane D, Ball S, Bichet D, et al. Clinical practice guideline on diagnosis and treatment of hyponatraemia. Nephrol Dial Transplant Off Publ Eur Dial Transpl Assoc - Eur Ren Assoc Apr 2014;29(Suppl. 2):i1-i39.

[6] Schrier RW, Sharma S, Shchekochikhin D. Hyponatraemia: more than just a marker of disease severity? Nat Rev Nephrol Jan 2013;9(1):37-50.

[7] Hoorn EJ, Lindemans J, Zietse R. Development of severe hyponatraemia in hospitalized patients: treatment-related risk factors and inadequate management. Nephrol Dial Transplant Jan 1 2006;21(1):70-6. 
[8] Schrier RW, Abraham WT. Hormones and hemodynamics in heart failure. N Engl J Med 1999;341(8):577-85.

[9] Robertson GL. The use of vasopressin assays in physiology and pathophysiology. Semin Nephrol Jul 1994;14(4):368-83.

[10] Szinnai G, Morgenthaler NG, Berneis K, Struck J, Muller B, Keller U, et al. Changes in plasma copeptin, the C-terminal portion of arginine vasopressin during water deprivation and excess in healthy subjects. J Clin Endocrinol Metab Oct 12007 92(10):3973-8.

[11] Bolignano D, Cabassi A, Fiaccadori E, Ghigo E, Pasquali R, Peracino A, et al. Copeptin (CTproAVP), a new tool for understanding the role of vasopressin in pathophysiology. Clin Chem Lab Med CCLM FESCC Oct 2014:52(10):1447-56.

[12] Morgenthaler NG, Struck J, Alonso C, Bergmann A. Assay for the measurement of copeptin, a stable peptide derived from the precursor of vasopressin. Clin Chem Jan 1 2006;52(1):112-9.

13] Schrock JW, Glasenapp M, Drogell K. Elevated blood urea nitrogen/creatinine ratio is associated with poor outcome in patients with ischemic stroke. Clin Neurol Neurosurg Sep 2012;114(7):881-4.

14] Leibovitz A, Baumoehl Y, Lubart E, Yaina A, Platinovitz N, Segal R. Dehydration among long-term care elderly patients with oropharyngeal dysphagia. Gerontology 2007;53(4):179-83.

[15] Miura M, Sakata Y, Nochioka K, Takahashi J, Takada T, Miyata S, et al. Prognostic impact of blood urea nitrogen changes during hospitalization in patients with acute heart failure syndrome. Circ J 2013;77(5):1221-8.
[16] Milionis HJ, Liamis GL, Elisaf MS. The hyponatremic patient: a systematic approach to laboratory diagnosis. Can Med Assoc J Apr 16 2002;166(8):1056-62.

[17] Oster JR, Singer I. Hyponatremia, hyposmolality, and hypotonicity: tables and fables. Arch Intern Med Feb 22 1999;159(4):333-6.

[18] Sebbane M, Lefebvre S, Kuster N, Jreige R, Jacques E, Badiou S, et al. Early rule out of acute myocardial infarction in ED patients: value of combined high-sensitivity cardiac troponin $\mathrm{T}$ and ultrasensitive copeptin assays at admission. Am J Emerg Med Sep 2013;31(9):1302-8.

[19] Musch W, Thimpont J, Vandervelde D, Verhaeverbeke I, Berghmans T, Decaux G. Combined fractional excretion of sodium and urea better predicts response to saline in hyponatremia than do usual clinical and biochemical parameters. Am J Med Oct 1995;99(4):348-55

[20] Robertson GL. Antidiuretic hormone. Normal and disordered function. Endocrinol Metab Clin North Am Sep 2001;30(3):671-94 [vii].

[21] Robertson GL. Regulation of arginine vasopressin in the syndrome of inappropriate antidiuresis. Am J Med Jul 2006;119(7 Suppl. 1):S36-42.

[22] Keller T, Tzikas S, Zeller T, Czyz E, Lillpopp L, Ojeda FM, et al. Copeptin improves early diagnosis of acute myocardial infarction. J Am Coll Cardiol mai 2010;55(19): 2096-106.

[23] Fenske W, Störk S, Blechschmidt A, Maier SGK, Morgenthaler NG, Allolio B. Copeptin in the differential diagnosis of hyponatremia. J Clin Endocrinol Metab Jan 2009; 94(1):123-9. 